\title{
Sobre los orígenes comerciales del Consulado de Veracruz: comercio libre y mercado interno a fines del siglo XVIII (1778-1795)
}

\section{El escenario previo}

El puerto de Veracruz, que en su ubicación actual se remonta a 1599, se desarrolló a lo largo de los siglos XVII y XVIII de una manera desigual y fluctuante, convirtiéndose en "la precisa garganta y paso" del comercio marítimo y terrestre del México colonial. A lo largo de los años, Veracruz fue creando en su litoral interior -a barlovento y sotavento- un variado mercado interno de abasto y zona de influencia, extendiendo además sus redes hacia Puebla, la ciudad de México, Acapulco y las provincias internas y alcanzando su máximo esplendor hasta la segunda mitad del siglo XVIII. Desde su legalización en 1599, la ciudad de la Nueva Veracruz gozaba de una posición de monopolio, pues era la única salida marítima legal de los productos mineros, artesanales y agrícolas de toda la Nueva España, ${ }^{1}$ así como la puerta exclusiva de lo que venía de Europa, el Caribe y África.

Sin embargo, los rasgos principales de la compleja vida del puerto se maduraron indudablemente en la primera mitad del siglo XVII, periodo caracterizado además por una larga depresión de la economía europea, la cual se expresó de manera diferente en América y terminó por reflejarse en la disminución del tráfico marítimo del puerto. Se trata de un siglo cuyos detalles a menudo sorprenden, pues fue durante esta larga centuria cuando el principal puerto marítimo de la Nueva España se convirtió en el desembarcadero más importante de la Carrera de Indias, en el eje de lo que se ha llamado "el Caribe andaluz" y en

Me refiero a la fundación en su última ubicación, a partir de la Antigua Veracruz, aceptada oficialmente hasta 1599, año en que se regularizó la traza de este nuevo emplazamiento ubicado en la llamada Banda de Buitrón, playa inhóspita situada frente al islote de San Juan de Ulúa. 
el principal punto de enlace de la Tierra Firme americana con Europa, África y Asia (Chaunu 1960). Vivió también, entre 1580 y 1640 el auge más importante de la trata negrera de los asientos portugueses, los ataques y asedios de los piratas, el tráfico comercial ampliado, el fraude sistemático en el funcionamiento de sus Cajas Reales, etc. Así, sobre el entramado de esta gran estructura, se levantó una vida económica pujante que sufrió durante los siglos XVII y XVIII muy importantes transformaciones, pero que en gran medida giraba sobre una plataforma de "economía sumergida", movida por el contrabando y el fraude en pequeña y gran escala, que lograba esquivar la vigilancia de las finanzas reales (García de León 1997).

Llama la atención, entonces, la fragilidad material de la llamada "ciudad de Tablas", su carácter casi efímero y episódico, en relación con la creciente magnitud de su tráfico marítimo y comercial (García de León 1998). Esta sencillez aparente contrastaba con el monto de las transacciones comerciales, financieras y usureras que se realizaban todo el año y con la existencia, desde 1599, de una Lonja de Comerciantes -dominada en el siglo XVII por los portugueses residentes-, que regulaba los precios de los principales productos. ${ }^{2}$ Sobresale también por el alcance mundial de su presencia marítima, y por contar con una traza urbana, establecida por el Cabildo desde 1604, que le daba un aspecto de mucho mayor fortaleza e institucionalidad de la que era posible percibir a simple vista. ${ }^{3}$ Después de la guerra de Sucesión y de la paz de Utrecht, firmada en 1713, Veracruz vivió un periodo de relativo auge del comercio exterior, basado principalmente en la presencia de la Real Compañía de Inglaterra, que introducía esclavos negros, del Caribe inglés en su mayoría, y que de hecho lo estuvo haciendo hasta 1737, cuando estallara un nuevo conflicto con Inglaterra. La actuación de la Real Compañía en Veracruz, la cual influyó fuertemente en el comercio local, en el contrabando y en el control casi exclusivo de la feria de Jalapa, obligó también, y por motivo de estos nuevos riesgos militares, a fortificarla nuevamente, a reforzar la condición de la débil muralla, a mejorar la defensa con el apoyo de milicias de negros y

2 Reglamento y título para los corredores de la Lonja de Veracruz, AGNM, Reales Cédulas Originales 1599. Mencionado también en Arcila Farías (1975: 162-165).

3 Para que el castellano y oficiales reales y Cabildo de San Juan de Ulúa informen sobre lo que pretende el dicho Cabildo sobre que se ponga en execución la nueva traza, 30 de enero de 1604, AGNM, General de Parte 6, exp. 960, f. 336v. 
mulatos, y a propiciar la creación de un sistema múltiple de vigías que permitieran una respuesta más efectiva en caso de un ataque masivo de los ingleses (García de León 2001).

Joseph Antonio de Villaseñor y Sánchez (1992 [1746-48]), en el año de 1743, describió la extensión de la ciudad de Veracruz, el número de sus vecinos, la naturaleza de sus edificios y la dificultad que seguían constituyendo tanto los vientos huracanados del norte, que la azotaban permanentemente, como la agudización de las periódicas epidemias de fiebre amarilla o vómito negro, que causaban el abandono de la región y que se habían iniciado desde el tiempo de los portugueses. La ciudad contaba entonces con unas sesenta familias de españoles y mulatos en el centro urbano, y unas cuatro mil personas más, distribuidas al interior de la muralla: es decir, apenas se reponía de lo que había sido su población casi un siglo antes. Otro censo del mismo 1743 sumaba 4,503 habitantes. Ya para entonces, la ciudad empezaba a crecer hacia afuera del recinto amurallado.

Durante los años posteriores, y antes del periodo de las reformas borbónicas, iniciadas allí con la llegada de José de Gálvez y de Juan de Villalba, que fueron enviados por Carlos III en 1767 para instaurar una serie de abruptos cambios, que incluían la reorganización de las defensas armadas y la creación de un ejército unificado, Veracruz vivía también varias turbulencias en su costa interior, en lo que sería uno de los circuitos de su propio mercado interno. Estas turbulencias tenían que ver principalmente con las dificultades que entonces atravesaba la feria de Jalapa, así como la región vecina de producción intensiva de azúcar que rodeaba a la villa de Córdoba, y que surtía del dulce a la capital del virreinato. Pero sobre todo, se asocian a las inquietudes creadas por la huida de los negros esclavos de las plantaciones azucareras hacia regiones del interior, creándose varios mocambos de cimarrones en la frontera con Oaxaca. La posterior integración de estos fugitivos a las milicias de defensa del puerto y del litoral fue producto de la efectividad de las reformas de Villalba, y de una nueva concepción de la defensa que pudo aprovechar a un sector de la población que generalmente había sido relegado por sus orígenes étnicos y raciales.

Este periodo de transición, que corre hasta la implantación de las reformas borbónicas, está así fuertemente marcado por la amenaza de los ingleses en el Caribe, por la toma de La Habana en el año de 1762, 
y por la presencia de una serie de problemas asociados a la guerra entre España e Inglaterra. En realidad, la decadencia del sistema de flotas, el fin del monopolio de Sevilla, y posteriormente del de Cádiz en el comercio americano, crearon una relativa recesión inmediata en el comercio del puerto y en sus diversos "pisos de mercadeo". Podemos decir, sin embargo, que la situación del puerto mejoró sensiblemente a partir de 1778 , cuando las reformas implantadas por José de Gálvez adquirieron una verdadera proyección en su vocación mercantil, y también cuando la aceptación institucional de las milicias, el mejoramiento de su defensa, etcétera, dieron lugar a la creación de otras baterías y fortalezas en el litoral de la costa vecina de Sotavento: medidas de seguridad que favorecieron las condiciones para un mejor desarrollo del propio mercado inmediato. No cabe duda que el comercio libre, implantado desde 1778, abrió para Veracruz nuevas perspectivas de desarrollo, en un periodo que se inició entonces y que parece haber concluido en 1795 con la fundación del Consulado, y que quisiéramos resumir de la siguiente manera (Ortiz de la Tabla Ducasse 1992):

De principio, a lo largo del XVIII hubo un notable incremento del tonelaje de mercancías de las flotas y los registros libres, así como del comercio en general. Entre 1717 y 1738 , en la época de la hegemonía de la Real Compañía de Inglaterra y de su navio de permisión de 600 toneladas, el monto totalizó las 46,423 toneladas y en los primeros 16 años de los registros sueltos esta cantidad casi se duplicó, alcanzando las 82 mil toneladas. Durante la segunda etapa de flotas, en los 24 años que corren de 1755 a 1778, el tonelaje llegó a las 83 mil toneladas: es decir que casi se duplica con relación al primer periodo, pero se percibe un retroceso con respecto al lapso de los registros sueltos. En cuanto al número de navíos, entre 1717 y 1812 el aumento fue considerable, siendo muy notorio en el periodo inmediatamente anterior a la creación del Consulado, lo que también justificó su erección. 


\section{Cuadro 1: Movimiento naval en el puerto de Veracruz}

\begin{tabular}{lcc}
\hline Periodos & Número de navios & Media anual \\
\hline $1717-1738$ & 112 & 5 \\
$1739-1754$ & 162 & 10 \\
$1755-1778$ & 173 & 7 \\
$1784-1795$ & 540 & 45 \\
$1802-1812$ & 801 & 72 \\
\hline
\end{tabular}

Fuente: Ortiz de la Tabla Ducasse (1992: 266).

\section{El fin de las flotas y el auge del comercio libre}

Generalmente, cuando se habla del Consulado de Veracruz, que fue creado en 1795, da la impresión de que esta agrupación de comerciantes hubiera surgido de la nada, cuando en realidad tiene profundas raíces en la Lonja creada en 1599: gremio organizado que tuvo una actuación importante en la regulación del comercio regional durante por lo menos 190 años, atravesando por varios periodos de auge y de recesión. ${ }^{4}$ Esta Lonja de tratantes no ha sido estudiada y es generalmente olvidada, aun cuando tiene periodos muy documentados, sobre todo en la segunda mitad del siglo XVII. Posiblemente por influencia de lo que ocurría en el Consulado de México, la Lonja de Veracruz estaba dividida, y precisamente en el periodo que nos ocupa, por dos partidos a menudo enfrentados entre sí, el de los montañeses y el de los vizcaínos. La Lonja constituye pues un antecedente importante para entender la complejidad del comercio veracruzano en los años inmediatamente anteriores a la creación del Consulado. Así, antes de 1770 , en este grupo de comerciantes prominentes de Veracruz predominaban una mayoría de inmigrantes de la península ibérica: primeramente, los de origen vasco, y después, una fuerte y creciente presencia de los montañeses, principalmente de Santander (Booker 1988). Es hasta el fin del periodo colonial cuando aparece un importante grupo

Souto Mantecón (1999) asegura incluso que en los siglos XVI y XVII, Veracruz "careció de una comunidad mercantil propia, que residiera en el puerto y que actuara por y desde él". 
de mercaderes catalanes asociados a diversas compañías de Barcelona y Girona. ${ }^{5}$ Esta fuerte presencia del norte de España nos habla también de una recomposición del comercio ocurrida a finales del periodo de los Austria y del ocaso de la Carrera andaluza: es, de hecho, un reflejo de los cambios sociales en la metrópoli que marcarían el nuevo destino del comercio de la Nueva España.

La Lonja crea, a pesar de sus luchas intestinas, las condiciones para que un gremio de comerciantes pueda defender sus intereses de manera unificada, y sin ella no se explica la creación de un consulado. Posiblemente, la mejor muestra de esta organicidad del comercio se pueda resumir en la famosa representación dirigida al rey en 1781 por varios comerciantes del lugar y destinada a presionar unificadamente a las autoridades de la metrópoli para romper el monopolio del comercio de la ciudad de México, creado desde el siglo XVI alrededor del único consulado permitido hasta entonces. Esta solicitud va a cristalizar hasta 1795 con el apoyo del virrey, el segundo conde de Revillagigedo. Lo importante de todo esto, y más allá de los acontecimientos menores que marcaron este ascenso, es que el volumen de la masa mercantil circulante se incrementó sensiblemente a partir de 1770; y fue en 1777 cuando el capitán Miguel del Corral (posteriormente gobernador de la plaza y quien habría de realizar aquella relación destinada a cuantificar los recursos de Veracruz y la costa de Sotavento) se decidió a planear la construcción de un astillero, a promover las manufacturas y a calcular los costos de un desarrollo basado en la explotación de las maderas que se deberían extraer de las selváticas cuencas fluviales, y las que, según él, estaban desaprovechadas o se trasladaban al astillero de La Habana (Siemens/Brinckmann 1976). El interés por la urbanización del puerto, por el acondicionamiento del muelle, por propiciar un crecimiento ordenado a extramuros y por el mejoramiento de los caminos hacia la ciudad de México se explica también en este contexto de reanimación del comercio.

También, si consideramos el ritmo de crecimiento de la economía del puerto, veremos que ésta se encontraba fundamentalmente ligada al comercio. El auge contemporáneo en la producción de plata y el

Llovet (1974); de hecho, es el comercio catalán el que desde 1780 impulsa la producción de algodón en la región de Tlalixcoyan, destinado a la industria textil de Barcelona. 
crecimiento de la población y del mercado interno explican mucho de este impulso, dando la impresión de que ocurre por primera vez, de manera aislada y sin antecedentes en el pasado regional. Garavaglia y Grosso, al estudiar el comportamiento de las alcabalas, han hecho notar que mientras la Nueva España tuvo un porcentaje de crecimiento, entre 1778 y 1785 , del $29,5 \%$ en el cobro de este impuesto sobre la circulación, Veracruz alcanzó el 56,1\%. Este comportamiento es además único, porque es el de un caso aislado en toda la parte oriental de la Nueva España. Esta dinámica es asimismo confirmada por otros indicadores. Los diezmos de Veracruz aumentaron de 42.362 pesos en 1775 a 98.546 en 1790 . Así, su participación porcentual en la masa de diezmos del obispado de Puebla, al que pertenecía, pasó del 15,03\% en 1775 , al $26 \%$ en 1790 . Si tomamos otros rubros, como el impuesto de avería o el crecimiento demográfico del casco urbano, el comportamiento es similar (Garavaglia/Grosso 1987).

\section{Los tres niveles del mercado interno y externo de Veracruz ${ }^{6}$}

Para referirnos al mercado propiamente dicho, uno de los factores sobresalientes que caracterizan a la intendencia de Veracruz fue la inexistencia para esa época de un solo núcleo urbano que dominara el desarrollo regional, como sucedía en México, Puebla, Oaxaca o Guadalajara. Por el contrario, en Veracruz la actividad económica se desarrollaba en varios polos interconectados, ubicados todos en el centro de la intendencia: Orizaba, Córdoba, Jalapa y Veracruz, que habían establecido relaciones diferenciadas con la capital del virreinato, bajo el impulso de actividades especializadas (en ese orden, comercio al menudeo, suministro de azúcar, feria y desembarcadero). En realidad, el puerto era el centro de toda esta actividad multipolar, que, podemos decir, se desarrollaba en tres niveles: tres pisos a menudo poco comunicados entre sí y que dan la impresión de mayor autonomía de la que realmente gozaban. Estos niveles mostraban también comportamientos diferentes, respondiendo a modelos de ordenación diversos, tanto que incluso hoy es posible estudiarlos de manera separada, detectarlos

Las conclusiones de esta parte están tomadas del análisis que hemos hecho de varios ramos del AGNM, el AHCV y los archivos municipales de Tlacotalpan y Acayucan, véase García de León (en preparación), Tierra adentro, mar en fuera. Veracruz y costa de Sotavento, 1519-1922. 
de manera diferencial por el tipo de fondos documentales y archivos que los mencionan y los agrupan. ${ }^{7}$

Primeramente, existía un mercado interno regional, desplegado hacia una parte de la franja norte del litoral (la costa de Barlovento) y, sobre todo, hacia el litoral sur hasta los límites meridionales de la intendencia (la costa de Sotavento, descrita por Corral y Aranda en 1777). Este mercado estaba conformado muy claramente por "anillos", como los que serían descritos poco después por von Thünen, y los cuales fueron claramente detectados y descritos por el barón de Humboldt en su estancia en el puerto hacia 1801, con base en los registros del Ayuntamiento. Los contornos de esos anillos se pueden constatar hoy en los fondos del Archivo Histórico de la ciudad, que se ocupan sobre todo de los asuntos del Cabildo y del abasto a la ciudad, y que son en gran medida documentos que utilizó el mismo Humboldt para fundamentar sus apreciaciones. Estos círculos concéntricos involucran a otros centros o polos, como las ciudades anteriormente mencionadas, así como a pueblos más pequeños, y se entreveran con todo un sistema de mercado regional de aspecto dendrítico, sobre todo en su despliegue hacia y desde el sur.

Pero veamos primero los anillos. El más vecino al puerto era de agricultura intensiva de hortalizas y pesca marítima menuda, y había sido creado desde fines del XVI -y con base en varias ordenanzas reales emitidas $a d$ hoc- para permitir que los negros libres que abastecían al puerto lo hicieran dentro de la legislación vigente (que generalmente prohibía a los africanos y sus descendientes estas actividades). En parte fue el despoblamiento indígena lo que permitió esto. Para fines del XVIII los agricultores de esta franja eran principalmente mulatos y, posteriormente, inmigrantes blancos de las islas Canarias. Después, seguía un segundo círculo de granjas lecheras y de productos artesanales, en el cual destacaban algunas pequeñas localidades, como La Antigua y la villa de Medellín. El tercer anillo era un poco más ancho y lo ocupaban ranchos aislados de agricultura de maíz y otros productos agrícolas, principalmente, y en él se hallaban, entre otros, antiguos pueblos de indios (convertidos ya entonces en pueblos de

Por ejemplo, para el comercio exterior, varios ramos del AGNM: Marina, Consulados, Correspondencia de diversas autoridades, etc. Para el mercado de abasto al puerto en sus anillos interiores, el AHCV. 
mulatos), como Tlalixcoyan, La Rinconada y Cotaxtla. Por último, y con una conformación irregular que iba por todo el interior hacia el sur de las tierras bajas del litoral de Sotavento, se extendía un anillo de grandes haciendas ganaderas -en su mayoría antiguos mayorazgos-, como la Estanzuela, el Mayorazgo de Guerrero y Nopalapan, que se entreveraban con pueblos de indios y mulatos en el Papaloapan, el río San Juan Michapan, y parte de la cuenca del Coatzacoalcos o región de Acayucan. Este último circuito introducía sobre todo ganado en pie para el abasto de la ciudad portuaria y para el consumo de las otras ciudades del centro de la intendencia. Junto con el anterior, eran la base de una ganadería extensiva, alimentada con mano de obra de algunos esclavos (la mayoría de ellos de "nación mandinga") y muchos negros y mulatos libres, especializados en la cría del ganado y en conducirlo a gran distancia (a veces hasta Puebla, México y Toluca), guiándolo a "punta de garrocha", usando salvedades a las ordenanzas que prohibían a los africanos y sus descendientes andar en grupo y armados. Estos vaqueros afromestizos, numerosos en el siglo XVIII según varias evidencias, son los originales "jarochos" de Sotavento, un grupo social étnicamente diferenciado a fines de la Colonia, que serían el principal contingente humano de las milicias primero, y de las tropas insurgentes después, así como un importante núcleo generador de cultura regional.

La estructura arborescente de este mercado interno regional confluía en el puerto y tenía a las otras ciudades como sustento secundario. Incluía centros menores de distribución y varias "bodegas" bien establecidas, como Tlalixcoyan, las de los Tuztlas (Otapa y Totoltepec), El Paso de San Juan y Acayucan, así como toda una red de distribución que desembocaba en el puerto siguiendo los cursos de los ríos. Para el siglo XVIII estos ríos eran conscientemente utilizados y se intentó incluso la construcción de un canal para unir la laguna de Alvarado con el río Blanco y la laguna de Mandinga, y hacer confluir este canal en el puerto. En esta red, ciudades como Córdoba o la alejada Villa Alta, en la sierra de Oaxaca, cumplían el papel de centros subsidiarios, y permitían el abasto de frutas, pescados, fibras, cueros, etcétera, así como recogían parte de la grana y el añil que venían de Oaxaca, Chiapas y Guatemala, usando los afluentes del río Papaloapan para llegar al puerto. Aquí, y justo en el medio de la gran cuenca, se erigía la villa de Tlacotalpan, la que aduciendo este papel de lugar 
estratégico, se había rehusado a desaparecer a principios del siglo XVII. La misma región de Córdoba era una especie de enclave azucarero anómalo incrustado en la región: se concentraban allí trapiches e ingenios para el azúcar del abasto novohispano, con una estructura interna de plantación azucarera caribeña, de explotación intensiva de la fuerza de trabajo esclava, que fue el principal centro de producción de negros cimarrones durante el último siglo colonial. Hoy es posible representar en un mapa las ciudades principales, los pueblos de mercado al mayoreo y al menudeo, las bodegas y los puertos de mar y muelles fluviales (como Alvarado y Tlacotalpan) que conformaban esta compleja red de flujos de ida y vuelta de más de un centenar de tipos de mercancía. La mayor parte de estos recorridos eran acuáticos y se realizaban en todo tipo de embarcaciones.

El segundo piso del complejo mercado del puerto era el entonces llamado de "tierra adentro", que constituía una estructura de "chimenea" en el comercio que venía del interior, del altiplano y de las regiones más lejanas, y que se agolpaba en Veracruz para la exportación. La feria de Jalapa había sido su principal motor desde principios del siglo, así como la feria del cacao venezolano que se efectuaba en el puerto desde el siglo anterior. Una red de arrieros a gran distancia lo animaba hasta la llegada al puerto, y parte de su larga extensión se continuaba en una amplia malla de comercio de cabotaje que iba por todo el litoral del Golfo hasta el puerto de Campeche, pasando por el sur de Veracruz y Tabasco. De regreso, una red de botes y fragatas introducía cera, maíz y sal de esa región y de la península de Yucatán, así como cacao de Tabasco, penetrando por los ríos que hallaba a su paso, como el Coatzacoalcos, para introducir legal e ilegalmente estos productos, a veces mezclados con mercancías del contrabando inglés. Esta red de cabotaje había sido creada desde el XVII por piratas menores y baymen, que fueron el quebradero de cabeza de las autoridades fiscales por más de dos siglos, y a quienes se debe incluso el despoblamiento del litoral y la destrucción de las antiguas villas españolas de la costa (como Santa María de la Victoria o la del Espíritu Santo). Pero para el siglo XVIII esta malla de cabotaje era ya el principal criadero de mercachifles y caciques indios, blancos y mulatos, con intereses diversos y encontrados en todo el litoral. En ciertos momentos, como en los interludios que permitían las treguas con Inglaterra, estas redes se extendían hasta la Florida (Panzacola y San Agus- 
tín), e incluso al puerto de La Habana, visto por su cercanía como un puerto novohispano (García de León 1996). ${ }^{8}$

Sin embargo, el "alojamiento" más importante del comercio local, y en donde se halla la clave de la supervivencia del puerto, a pesar de las enormes limitaciones naturales, militares y sociales para su implantación, era el gran comercio marítimo o de "mar en fuera". Sin este nivel de relaciones, caracterizado por el monto de su valor real, Veracruz no hubiera sobrevivido. En el ramo Marina, del Archivo General de la Nación de México, se halla parte de la conformación de este nivel superior que conectaba a Veracruz con todo el mundo conocido desde finales del siglo XVI, sobre todo en los detallados registros, buque por buque, de las mercancías de ida y vuelta que cubren los recorridos a través del Atlántico hacia Sevilla, el resto de Europa y África; y por la vía terrestre hacia Acapulco. Estas redes nerviosas atraviesan el Pacífico hacia las islas Filipinas, así como hacia el Perú, Guayaquil, el norte de Chile y el Río de la Plata. Su estructura trasciende al imperio español y llega hasta las Guyanas, el Brasil, los puertos italianos o los demás del Mediterráneo, así como los de la costa del Atlántico en Francia (Bayona, Burdeos, Ruán...) y, por supuesto, Amberes y Amsterdam. Este complejo nudo de relaciones a gran distancia se desarrolló con especial fuerza desde el "periodo portugués", aunque se recompuso constantemente. Prácticamente, se debe a las antiguas redes portuguesas, destruidas en 1642, el contacto de Veracruz con la economía-mundo, haciéndola participar de los primeros procesos de globalización.

En un sentido mucho más estricto, este nivel de relaciones principalmente portuarias y marítimas también convirtió a Veracruz en uno de los puertos más importantes de la Carrera de Indias y del gran Caribe, sobre todo a través de los más conocidos circuitos de intercambio de plata labrada, acuñada y en pasta, oro, harinas y trigo -a través de los situados o suministros de la Nueva España al Caribe insular y de Tierra Firme-, así como en un centro de intercambio de experiencias en lo tocante a milicias, presidios, defensa militar y cultura popular entre 1767 y 1775 (García de León 1999).

Varios ramos del AGNM contienen información muy precisa sobre estas vinculaciones movedizas. 
Este inmenso "piso de mercadeo" convirtió a Veracruz en una ciudad, aunque su apariencia fuera, hasta 1746, más la de una aldea que la de una concentración urbana, aun cuando esta característica deba ser tomada con mucho mayor cuidado. Lo importante aquí es que esos niveles, a menudo incomunicados entre sí, se movieron de manera mucho más encadenada en las décadas posteriores a 1778, llevando a un crecimiento nunca visto de la actividad comercial del principal puerto novohispano, el cual a través del Consulado habría incluso de intentar administrar de manera más racional estas redes. Es decir que en el momento en que estas tramas, por razones más bien políticas y en función de la creación de la intendencia, se vieron obligadas a comunicarse entre sí, el mismo mercado interno se vio fuertemente favorecido. Pero, paradójicamente, en este auge estaban muchos de los gérmenes de la ruina del puerto y de su decadencia posterior. La "superestrella" del comercio marítimo de la época creció tal vez de manera demasiado rápida; y se convirtió, después de la independencia, en una "enana blanca" cuyos apagados reflejos eran apenas perceptibles a mediados del siglo XIX.

Podemos también decir, en relación con el nivel más amplio de intercambio de mercancías y dinero, y con respecto a lo que significó para la ciudad de México la creación en 1795 de dos consulados rivales -el de Veracruz y el de Guadalajara-, que esto encaja con el desarrollo del propio mercado interno del puerto, pues, a partir de entonces, Veracruz pudo especializarse más en el comercio de "mar en fuera", mientras que Guadalajara se convirtió en el principal aliado y "factor" de los comerciantes veracruzanos en el comercio de "tierra adentro" y hacia las llamadas Provincias Internas del gran norte. La alianza de los dos Consulados, a más de política, es, sobre todo, la de una combinación bastante exitosa en la división mercantil de la Nueva España de entonces (Ibarra 2000b).

Por último, este tráfico comercial estuvo bañado de siglos de maduración común, permitiendo al espacio geográfico del Caribe compartir toda una serie de flujos de transmisión cultural y responder de manera similar ante los retos de la naturaleza, la velocidad de los cambios y los procesos de reformas que se aceleraron en la segunda mitad del siglo XVIII, así como en la adaptación a las más cambiantes circunstancias. Los hinterland y mercados interiores de otros puertos, como La Habana, Santiago, San Juan de Puerto Rico, Santo Domingo, 
Portobelo, Caracas o Cartagena de Indias - por sólo mencionar la parte española de un fenómeno mucho más multinacional y multicultural-, generaron estructuras sociales muy similares entre sí, que respondían de hecho a una singular y sólida red de intercambios, cuyos vestigios van a pervivir precisamente en el terreno de las preferencias culturales y mentales (García de León 1992). Es por ello que la historia económica del puerto y del litoral que le dio cobijo no puede ser reconstruida sin el componente de la vida cultural y de un tipo de mentalidad que produjo después una importante camada de pensadores liberales y de nuevos impulsores del comercio. 